\title{
NILAI ESTETIK TARI SRIMPI PANDHELORI DI PURA MANGKUNEGARAN
}

\author{
Sriyadi \\ nstitut Seni Indonesia (ISI) Surakarta \\ Jalan Ki Hadjar Dewantara No. 19 Kentingan, Jebres, Surakarta 57126 \\ Wahyu Santoso Prabowo \\ Institut Seni Indonesia (ISI) Surakarta
}

\begin{abstract}
Abstrak
Penelitian Nilai Estetik Tari Srimpi Pandhelori di Pura Mangkunegaran bertujuan untuk mendeskripsikan koreografi dannilai estetik tari Srimpi Pandhelori. Analisis koreografi Srimpi Pandhelori menggunakan konsep koreografi Sumandiyo Hadi. Analisis nilai estetik menggunakan konsep nilai estetik menurut The Liang Gie, yang didukung dengan konsep ciri-ciri sifat benda estetik oleh Monroe Beardsley, dan konsep pengungkapan nilai-nilai kehidupan dalam karya seni oleh De Witt H. Paker. Penulisan skripsi ini menggunakan metode penelitian kualitatif, dengan pendekatan estetik. Teknik pengumpulan data yang digunakan adalah observasi, wawancara, dan studi pustaka. Hasil penelitian menunjukan bahwa tari Srimpi Pandhelori memiliki nilai estetik karena dari sudut pandang inderawi memiliki nilai bentuk dan dari isi mampu mengungkapkan nilai-nilai kehidupan.
\end{abstract}

Kata kunci: Srimpi Pandhelori, koreografi, nilai estetik.

\begin{abstract}
Research Value Aesthetic Srimpi Pandhelori Dance in Pura Mangkunegaran aims to describe the choreography and aesthetic value of Srimpi Pandhelori dance. Srimpi Pandhelori choreography analysis uses Sumandiyo Hadi's choreography concept. Aesthetic value analysis uses the concept of aesthetic value according to The Liang Gie, supported by the concept of aesthetic properties by Monroe Beardsley, and the concept of life values in artwork by De Witt H. Paker. Writing this thesis using qualitative research methods, with an aesthetic approach. Data collection techniques used were observation, interview, and literature study. The results showed that the Srimpi Pandhelori dance has an aesthetic value because from the viewpoint of the senses have the value of the form and the content is able to express the values of life.
\end{abstract}

Keywords: Srimpi Pandhelori, choreography, aesthetic value.

\section{PENDAHULUAN}

Tari Srimpi Pandhelori di Pura Mangkunegaran adalah salah satu karya tari yang berhasil dipelajari oleh G.R.Ay. Siti Noeroel Kamaril Ngasarati
Koesoemawardhani dan beberapa kerabatnya di Kridha Beksa Wirama (KBW) Yogyakarta. Tari Srimpi Pandhelori pertama kali dipentaskan di Pura Mangku-negaran pada tahun 1935 yang di-tarikan oleh G.R.Ay. 
Siti Noeroel Kamaril Ngasarati Kusumawardhani, G.R.Ay. Partinah, R.Ay. Praptini, dan Ndhuk Nah yang merupakan seorang abdi dalem (Prabowo, dkk., 2007: 143-144).

Tari Srimpi Pandhelori menceri-takan peperangan antara Sudara-werti melawan Sirtupelaheli. Ke-duanya berperang karena saling berebut untuk menyelamatkan dan menikah dengan Amir Ambyah. Peperangan antara Sudarawerti dan Sirtupelaheli tidak ada yang kalah dan menang, akhirnya mereka bersatu dan berhasil menye-lamatkan Amir Ambyah (Umiyati, wawancara 4 Mei 2016).

Tari Srimpi Pandhelori di Pura Mangkunegaran pada dasarnya menggunakan bentuk-bentuk gerak gaya Yogyakarta, karena berasal dari Yogyakarta, namun teknik pelaksanaan gerak dan rasa yang disajikan tidak lagi seperti gaya Yogyakarta (Prabowo, dkk., 2007: 140). Perubahan bentuk gerak yang terdapat dalam tari Srimpi Pandhe-lori di Mangkunegaran disebabkan karena, bentuk tari gaya Yogya-karta yang disajikan oleh penari dengan kemapanan dan kemantapan tubuh gaya Surakarta.

Bentuk tari gaya Yogyakarta dan gaya Surakarta memiliki bentuk dan teknik gerak yang berbeda. Menurut Simatupang kondisi tubuh yang sudah dibiasakan pada teknik dan bentuk gerak merupa-kan salah satu pembatas untuk me-nerima teknik dan bentuk yang lainnya (Simatupang, 2013: 60). Gaya Surakarta yang terlebih dahulu digunakan di Mangku-negaran membentuk kemapanan dan kemantapan penari Mangku-negaran pada gaya Surakarta, sehingga penari di Mangkunegaran kesulitan terhadap teknik gerak gaya Yogyakarta. Atas perkenaan dan petunjuk K.G.P.A.A.
Mangku-nagara VII dan G.K.R. Timur, teknik dan bentuk gerak gaya Yogyakarta yang sulit dilakukan dirubah, supaya terkesan luwes dan enak dilakukan (Suharti, 1990: 95).

Perubahan teknik dan bentuk gerak gaya Yogyakarta yang disaji-kan oleh penari gaya Surakarta, menyebabkan tari Srimpi Pandhe-lori di Mangkunegaran memiliki kemantapan estetis tersendiri. Hal itu yang menyebabkan peneliti melakukan penelitian "Nilai Estetik Tari Srimpi Pandhelori di Pura Mangkunegaran". Di dalam pene-litian ini, peneliti menentukan dua rumusan masalah yaitu bagaimana koreografi Srimpi Pandhelori di Pura Mangkunegaran, dan bagai-mana nilai estetik tari Srimpi Pandhelori di Pura Mangku-negaran.

Analisis koreografi Srimpi Pandhelori di Pura Mangku-negaran menggunakan landasan teori elemen-elemen koreografi menurut Sumandiyo Hadi. Peneliti memahami menganalisis koreografi adalah menganalisis bentuk karya tari dengan memilah berbagai elemen-elemennya. Elemen-elemen koreografi menurut Sumandiyo Hadi terdiri dari judul tari, tema tari, tipe atau jenis tari, mode atau cara penyajian, penari, gerak, ruang, musik tari, tata rias dan busana, properti, serta tata cahaya (Sumandiyo, 2003: 86). Elemenelemen koreografi menurut Sumandiyo itu digunakan untuk menganalisis koreografi tari Srimpi Pandhelori di Mangkunegaran.

Landasan teori yang digunakan untuk menganalisis nilai estetik tari Srimpi Pandhelori di Pura Mangku-ngeran adalah teori nilai estetik menurut The Liang Gie. Menurut The Liang Gie, nilai estetik dalam sebuah karya seni terdiri dari bentuk yang memiliki nilai bentuk (inderawi), dan isi yang 
mampu mengungkapkan nilai-nilai kehidupan (Gie, 1976: 70-71). Nilai ben-tuk tari Srimpi Pandhelori diana-lisis dengan tiga ciriciri sifat benda estetik yang dikemukakan oleh Monroe Beardsley, yaitu kesatuan (unity), kerumitan (complexity), dan kesungguhan (intensity) (Kartika, 2007b: 63). Nilai-nilai kehidupan yang terdapat dalam tari Srimpi Pandhelori dianalisis dengan teori milik De Witt H. Parker. Menurut Parker nilainilai kehidupan se-bagai isi sebuah karya seni dapat dirasakan melalui lambang sensa, yang dibentuk dari medium ungkap yang digunakan. Lambang sensa itu membentuk sebuah rasa, dari rasa itu akan menuntun ima-jinasi penghayat untuk menangkap nilainilai kehidupan (Parker, 1979: 44-73).

Di dalam penelitian "Nilai Estetik Tari Srimpi Pandhelori di Pura Mangkunegaran" mengguna-kan metode penelitian kualitatif, dengan pendekatan estetik. Teknik pengumpulan data yang digunakan adalah observasi, wawancara, dan studi pustaka. Observasi yang dilakukan adalah observasi lang-sung partisipasi, dengan mengamati langsung dan mengikuti latih-an tari di PAKARTI dan Langen Praja Pura Mangkunegaran. Wa-wancara dilakukan oleh peneliti kepada beberapa narasumber tari gaya Mangkunegaran. Studi pus-taka dilakukan peneliti dengan membaca beberapa buku. Buku-buku itu dibaca dan kemudian informasi yang penting dikutip menurut kebutuhan.

\section{KOREOGRAFI SRIMPI PANDHELORI}

Kata pandhelori dalam tari Srimpi Pandhelori, merupakan judul yang digunakan untuk menyebut karya tari srimpi ini. Nama pandhelori diambil dari nama gending pokok yang digunakan, yaitu gendhing Pandhelori (Umiyati, wawancara 11 Oktober 2017).

Tema menurut Sumandiyo di-pahami sebagai pokok permasa-lahan, yang mengandung isi atau makna tertentu dari sebuah koreo-grafi (Sumandiyo, 2003: 89). Isi atau makna dalam sebuah karya tari dapat mengambil dari berbagai sumber cerita, peristiwa yang pernah dialami, maupun fenomena yang ada di lingkungan sekitar. Tema tari Srimpi Pandhelori di Mangkunegaran adalah keprajurit-an yang mengambil dari sebagian Cerita Menak. Bagian cerita yang diangkat yaitu peperangan antara Sirtupelaheli melawan Sudarawerti. Cerita Menak itu ditulis oleh R. $\mathrm{Ng}$. Yosodipura I dalam Serat Menak Kanjun.

Sumandiyo membagi tipe atau jenis tari menjadi tiga yaitu tradisi kerakyatan, klasik tradisional, dan modern/ kreasi baru (Sumandiyo, 2003: 90). Tipe atau jenis tari Srimpi Pandhelori adalah tari tra-disional klasik, karena tari Srimpi Pandhelori merupakan salah satu bentuk tari srimpi yang berkem-bang di keraton.

Mode atau cara penyajian koreografi pada hakekatnya dapat dibedakan menjadi tiga yaitu representtasional, simbolis, dan representasional-simbolis. Perbeda-an itu dapat dilihat dari bentuk gerak yang digunakan, yaitu gerak representatif dan non-representatif (Sumandiyo, 2003: 90). Tari Srimpi Pandhelori di Mangkunegaran menggunakan mode penyajian representasional-simbolis, karena menggunakan bentuk gerak representatif dan non-representatif. Bentuk gerak representatif adalah bentuk gerak yang maknanya mudah dipahami, seperti bentuk gerak tasikan, ulap-ulap cathok udet, perang nyuduk lambung, nyuduk dada, dan 
panahan. Bentuk gerak non-representatif yaitu bentuk gerak yang maknanya sulit untuk dipahami, namun memiliki kekuat-an ungkap yang bisa dirasakan, yaitu $n d u d u k$ wuluh, nggrudha, gudhawa, kipat gajahan, mlampah gajah ngoling, lembehan, trisig tinting encot, mlampah hoyok encot, ngenceng encot dan gidrah.

Penari dalam karya tari merupa-kan pendukung utama yang me-nentukan keberhasilan atau ke-mantapan sajian tari (Prihatini dkk., 2007: 70). Penari dalam sebuah karya tari dapat dirinci menjadi jumlah penari dan jenis kelamin. Tari Srimpi Pandhelori di Mangkunegaran disajikan oleh empat orang penari dengan jenis kelamin perem-puan. Setiap penari dalam tari Srimpi Pandhelori di Mangkune-garan memiliki peranan, yaitu batak, gulu, dhadha, dan buntil.

Tari Srimpi Pandhelori meng-gunakan adeg nggrudha, atau di Mangkunegaran disebut dengan adeg pacak kelir. Adeg adalah sikap badan yang digunakan pada saat menari. Posisi badan pada adeg pacak kelir adalah badan tegap, seperti badan yang ditempelkan di dinding, sehingga tidak condong ke depan, kemudian jaja atau dhadha mungal.

Di dalam melakukan adeg pacak kelir pada tari Srimpi Pandhelori di Mangkunegaran kedua lutut harus selalu ditekuk yang sering disebut dengan istilah mendhak, kecuali beberapa motif gerak yang mene-kankan garis lurus yang dibentuk dengan tungkai, sehingga lutut harus diluruskan. Mendhak adalah sikap menari dengan posisi tung-kai ditekuk, lutut dibuka ke sam-ping, kaki membuat sudut $90^{\circ}$ dengan arah kaki serong ke kanan dan ke kiri, jarak kedua kaki kurang lebih satu kepalan tangan. Bentuk jari-jari kaki pada saat menari adalah nylekenthing (Rusini, wawancara 12 Oktober 2017).

Tari Srimpi Pandhelori di Pura Mangkunegaran pada dasarnya menggunakan bentuk gerak gaya Yogyakarta, namun dilakukan oleh penari dengan ketubuhan gaya Surakarta, sehingga karena dibatasi oleh ketubuhan yang sudah mapan pada bentuk gaya Surakarta, terdapat beberapa bentuk gerak yang sulit dilakukan kemudian dirubah. Secara garis besar perubahan ben-tuk gerak yang sekarang dapat di-amati pada tari Srimpi Pandhelori adalah,

1. Bentuk gerak kepala ketika menoleh ke kanan atau ke kiri tidak terlalu miring. Teknik gerak kepala tidak menitik tekankan pada pangkal leher, namun pada ujung dagu.

2. Posisi tangan ketika trap cethik tidak nyiku, tetapi membuka $45^{\circ}$.

3. Bentuk gerak tangan tidak terkesan lurus-lurus dan patah-patah. Bentuk gerak tangan terkesan melengkung yang dilakukan mengalir, serta tidak banyak aksentuasi.

4. Penggunaan $u$ dhet tidak menggunakan teknik nyathok melainkan kebyok.

5. Bentuk gerak seblak dan nglawe tidak ke belakang, namun ke samping.

6. Tidak banyak menggunakan teknik ingsetan kaki ketika memindah berat badan.

7. Pada bentuk gerak trisig apabila belok menggunakan bentuk gerak mendhak.

8. Menggunakan desain kain samparan yang digerakan dengan cara diseblakan ke kanan dan ke kiri.

Menurut Sumandiyo Hadi sebuah karya tari memiliki motif gerak. Di dalam 
motif gerak itu ada yang merupakan motif gerak peng-hubung dan motif gerak pengulangan. Motif gerak penghubung adalah motif gerak yang digunakan untuk menghubungkan dari motif gerak satu ke motif gerak yang lainnya. Motif gerak pengulangan adalah motif gerak yang dilakukan lebih dari satu kali (diulang) dalam sebuah sajian karya tari (Hadi, 2003: 47-49).

Di dalam motif gerak tari Srimpi Pandhelori terdapat motif gerak penghubung dan motif gerak pengulangan. Motif gerak peng-hubung pada tari Srimpi Pandhe-lori adalah trisig, sendhi cathok udhet, sendhi nglawe, dan sendhi ongkek. Motif gerak pengulangan dalam tari Srimpi Pandhelori adalah kapang-kapang, jengkeng, sembahan sila, nggrudha kiri, mayuk jinjit kiri, pendhapan, enjer ridhong udhet, tasikan mubeng, tumpang tali kengser, kipat gajahan, gidrah, enjer ridhong udet, lembehan, mlampah gajah ngoling, mlampah hoyok encot, ngenceng encot, usap, perang nyuduk lambung, dan trisig tinting encot. Tari Srimpi Pandhelori juga meng-gunakan motif gerak yang tidak termasuk dalam gerak penghubung dan pengulangan yaitu nggrudha kanan, nggrudha mubeng, mayuk jinjit kanan, ngregem udhet kanan, dan sembahan ngleyang.

Ruang dalam sajian tari dapat dibedakan menjadi dua, yaitu ruang pentas dan ruang gerak. Ruang pentas adalah tempat yang digunakan penari dalam menyaji-kan karyanya. Ruang gerak adalah ruang yang terbentuk karena ada-nya gerakan yang dilakukan oleh penari. Ruang gerak dapat dibagi menjadi beberapa bagian yaitu ruang motif gerak, level, formasi, dan pola lantai (Sumandiyo, 2003: 23-27).

Tari Srimpi Pandhelori meng-gunakan ruang pentas di pendapa. Tetapi dalam perkembangannya ruang pentas tari Srimpi Pandhelori tidak memiliki kebakuan di pendapa. Meskipun tidak memiliki kebakuan pentas di pendapa, namun selama ini tari Srimpi Pandhelori lebih sering dipentas-kan di pendapa (Umiyati, wawan-cara 11 Oktober 2017).

Motif gerak tari Srimpi Pandhe-lori memiliki ruang atau volume kecil (sempit), karena disajikan dalam bentuk gerak tari putri. Level yang digunakan pada Tari Srimpi Pandhelori adalah level rendah dan level tinggi. Keempat penari tari Srimpi Pandhelori menggunakan level yang selalu sama, level rendah digunakan pada bentuk gerak jengkeng, sila, dan ndhodhok, selain itu penari meng-gunakan level tinggi.

Formasi atau gawang yang digunakan pada tari Srimpi Pandhelori adalah gawang rakit menghadap depan, gawang rakit berhadapan, gawang rakit adu kanan, gawang rakit adu kiri, urut kacang, dan gawang gingsul. Formasi atau gawang itu dibentuk dengan pola lantai melingkar, angka delapan, garis lurus ke depan, ke bela-kang, dan ke samping.

Bentuk musik tari atau karawitan tari Srimpi Pandhelori di Mangkunegaran pada dasarnya sama dengan bentuk karawitan tari Srimpi Pandhelori gaya Yogya-karta. Notasi yang digunakan adalah notasi gaya Yogyakarta, namun rasa garap yang muncul adalah gaya Surakarta. Hal itu disebabkan karena pengrawit di Mangkunegaran sudah mapan dan mantap dengan rasa garap gending gaya Surakarta (Suharti, 1990: 94).

Struktur sajian karawitan tari yang digunakan dalam tari Srimpi Pandhelori di Mangkunegaran adalah Lagon maju beksan, Ldr. Harjuna Mangsah, Gendhing Pandhelori Kethuk Loro Kerep Minggah Sekawan, Ldr. 
Manis, Ayak-ayak Cakrik Ngayogjakarta, Lagon Jugag, Ldr. Harjuna Mangsah, dan diakhiri Lagon mundur beksan (Hartono, wawancara 11 Oktober 2017). Laras yang digunakan dalam karawitan tari Srimpi Pandhelori adalah Laras Pelog Pathet Barang.

Tata rias tari Srimpi Pandhelori di Mangkunegaran adalah corrective make up, dengan penebalan pada warna alis, kelopak mata, tulang pipi, hidung, dan bibir, yang memberi kesan cantik (Slamet, 2014a: 137). Tata rias tari Srimpi Pandhelori menggunakan laler mencok, sogokan, dan godheg ngudhup turi yang dibuat dari pidih atau pensil alis berwarna hitam.

Kostum yang digunakan pada tari Srimpi Pandhelori di Mangku-negaran adalah jamang dengan motif untu walang, garudha mungkur, utah-utahan, kanthong gelung, bros, cundhuk jungkat, sumping, kalung penanggalan, giwang, gelang, kelat bahu, baju rompi tanpa lengan, udhet, slepe, thothok, sinjang sampa-ran, patrem, dan kolong patrem.

Properti tari adalah perlengkap-an yang seolah-olah menjadi satu dengan badan penari (Soedarsono, 1978: 36). Properti tari Srimpi Pandhelori di Mangkunegaran adalah jebeng, patrem, dan jemparing. Benda-benda itu adalah perleng-kapan yang ikut ditarikan oleh penari, untuk mendukung ekspresi yang ingin diungkapkan.

Jebeng digunakan pada saat perang patrem. Jebeng yang diguna-kan terdiri dari dua motif, perbeda-an kedua motif tersebut terletak pada bentuk wayang yang digunakan. Perbedaan motif pada jebeng digunakan untuk memperjelas dan membedakan tokoh yang ditampil-kan, yaitu Sirtupelaheli dan Suda-rawerti. Sirtupelaheli digambarkan dengan bentuk wayang seorang putri yang sedang menaiki burung garuda. Sudarawerti digambarkan dengan bentuk separuh wayang wanita bagian atas, dengan bentuk hiasan kepala pogog putri jamang lanyap. Patrem adalah bagian dari kostum, namun pada saat perang patrem, patrem menjadi sebuah properti. Penari dengan memegang gagang patrem dapat menggerakan patrem, sehingga seolah-olah men-jadi bagian tubuh penari. Jemparing digunakan pada bagian perang panahan. Jemparing terdiri dari beberapa bagian yaitu gendewa atau busur, kentheng, dan nyenyep.

Tata cahaya yang digunakan pada tari Srimpi Pandhelori di Mangkunegaran dari awal hingga akhir sajian adalah general lighting yang bersifat penerangan sepenuh-nya. General light dengan penerang-an sepenuhnya dapat menggam-barkan kemegahan dan mampu memperjelas ketampakan sebuah karya tari (Sumandiyo, 2003: 92).

\section{NILAI ESTETIK TARI SRIMPI PANDHELORI}

Estetika merupakan sebuah cabang filsafat mengenai keindah-an. Estetika berasal dari kata Yunani aesthetis, yang berarti perasaan atau sensitivitas. Hal itu menyebabkan estetika erat sekali hubungannya dengan selera pe-rasaan (Kartika dan Nanang, 2004: 16). Di dalam Kamus Besar Bahasa Indonesia, estetika adalah cabang filsafat yang menelaah dan mem-bahas tentang seni dan keindahan serta tanggapan manusia terhadap-nya.

Nilai dalam bidang filsafat sering digunakan sebagai kata benda abstrak yang berarti keberhargaan (worth) atau kebaikan (goodnes). Di dalam Dictionary of Sociology and Related Sciences diberi-kan perumusan mengenai sebuah nilai yang lebih terperinci 
lagi, yaitu sebagai kemampuan yang dipercayai ada pada suatu benda untuk memuaskan keinginan manusia. Sifat suatu benda yang menarik seseorang atau suatu golongan (Kartika, 2007b: 8).

Peneliti memahami sebuah benda atau barang memiliki nilai karena benda tersebut berharga, baik, dan dapat memberi kepuasan karena mampu membuat hidup manusia menjadi lebih baik. Sebuah karya seni memiliki nilai estetik karena medium ungkap karya seni tersebut mampu meng-ungkapkan sebuah kenikmatan yang dapat memenuhi kepuasan batin, mampu memberi kebahagia-an, serta kesenangan dalam ke-hidupan rohani manusia. Ke-nikmatan dalam sebuah karya seni diperoleh dari rasa yang diungkap-kan melalui medium ungkapnya.

Menurut The Liang Gie sebuah karya seni sebagai ciptaan manusia mempunyai nilai estetik untuk memuaskan suatu keinginan manu-sia. Nilai estetik karya seni dapat dirasakan dari nilai bentuk dan nilai kehidupan di luar seni yang mampu diungkapkan dalam sebuah karya seni. Nilai bentuk dapat dirasakan dari pengamatan indera-wi. Melalui bentuk karya tari penghayat dapat mengagumi dan me-nikmati sebuah keindahan. Nilai kehidupan adalah nilai-nilai dari kehidupan manusia di luar seni yang diteruskan sebagai isi melalui medium ungkap yang digunakan. Nilai kehidupan dapat diungkap-kan melalui sebuah rasa yang dibentuk dari medium ungkap. Keberhasilan pengungkapan itu akan menimbulkan kepuasan batin manusia (Gie, 1976: 70-71).

\section{Nilai Bentuk}

Nilai bentuk tari Srimpi Pandhelori dapat dirasakan dari tiga ciri-ciri sifat benda estetis. Tiga ciri tersebut yang disampaikan oleh Monroe Beardsley, yaitu kesatuan, kerumitan, dan kesungguhan.

\section{a. Kesatuan (unity)}

Kesatuan adalah hubungan timbal balik dari elemen-elemen yang membentuk karya tari. Setiap elemen-elemen saling menanggapi dan menuntut elemen lainnya, sehingga elemen itu tidak mampu untuk berdiri sendiri dan menjadi sebuah bentuk, tanpa dukungan dari elemen-elemen yang lain. Melalui kesatuan elemen-elemen dalam karya tari, penghayat mampu menangkap dan merasa-kan keindahan bentuk karya tari. Hal itu disebabkan, karena dengan adanya kesatuan elemen-elemen karya tari akan menjadi lebih hidup dan mampu mempertebal ungkap-an nilai yang dikandungnya. Ke-satuan medium ungkap tari Srimpi Pandhelori dapat dirasakan dari,

1. Hilangnya batasan-batasan antar motif gerak yang disusun (luluh).

2. Kesatuan penyusunan rasa gending dan rasa gerak yang digunakan.

3. Keharmonisan irama gending dan irama gerak yang diguna-kan.

4. Keserasian keempat penari, yang dapat dirasakan dari keempat penari dalam membawakan motif gerak, tempo, dan pe-laksanaan gerak yang sama, dengan kekuatan pengungkapan rasa yang sama.

Kesatuan medium ungkap tari Srimpi Pandhelori mampu meng-ungkapkan nilainilai kehidupan sebagai isi tari Srimpi Pandhelori.

\section{b. Kerumitan (complexity)}

Sebuah karya tari memiliki kerumitan karena di dalamnya memiliki 
berbagai aturan-aturan dan teknik-teknik dalam melaku-kannya. Aturan dan teknik diguna-kan untuk mencapai kualitas pengungkapan rasa dalam mewujudkan isi yang ingin diungkapkan. Tari Srimpi Pandhelori memiliki ke-rumitan, yang dapat dirasakan dari aturan dan teknik yang dibutuhkan dalam proses pengungkapan rasa melalui medium ungkapnya.

Setiap motif gerak yang digunakan dalam tari Srimpi Pandhelori memiliki kerumitan, karena adanya aturan-aturan yang telah ditentu-kan. Aturan-aturan itu dapat di-lihat dan dirasakan melalui bentuk, posisi atau tempat, dan proses perpindahan yang telah ditentukan. Di dalam setiap motif gerak juga sudah memiliki struktur yang ditetapkan. Struktur itu dapat dilihat dan dirasakan dari bagaimana cara mengawali motif gerak, kemudian diikuti gerak berikutnya, dan bagaimana cara mengakhiri pelaksanaan motif gerak itu.

Setiap pelaksanaan motif gerak tari Srimpi Pandhelori memiliki teknik. Teknikteknik tersebut di-gunakan untuk mencapai ketepatan wujud dari motif gerak, sehingga mampu mengungkapkan rasa. Tek-nik yang dimaksud berupa cara melakukan gerak dan pengaturan tempo gerak supaya sesuai dengan irama gending. Hasil dari penguasaan teknik dalam melakukan setiap motif gerak yang sesuai dengan irama gending, akan menimbulkan kemantapan rasa tari Srimpi Pandhelori.

Gending yang digunakan pada tari Srimpi Pandhelori memiliki kerumitan. Kerumitan tampak dengan dibutuhkannya kemampu-an mendalam para pengrawit untuk menyajikan gending tari Srimpi Pandhelori di Mangkunegaran. Kemampuan mendalam itu di-butuhkan, karena dalam menyaji-kan gending memiliki aturanaturan dan teknik-teknik yang harus dikuasai, serta harus me-nafsirkan gending yang disajikan.

Tata rias yang digunakan pada tari Srimpi Pandhelori memiliki ke-rumitan. Tata rias yang digunakan memiliki aturan-aturan yang me-nuntut untuk mengungkapkan kecantikan dan keanggunan wanita. Tata rias yang memberikan kesan cantik pada seseorang memerlukan teknik dan ketrampilan yang men-dalam, karena tidak mudah untuk merias seseorang sehingga mampu mengungkapkan kecantikan dan keanggunan.

Tata busana yang digunakan pada tari Srimpi Pandhelori di Mangkunegaran memiliki kerumit-an baik dari bentuk, motif, desain, susunan penggunaannya, pemilih-an perpaduan warna, serta cara pemakaiannya. Pemakaian busana tari Srimpi Pandhelori memiliki teknik-teknik. Teknik-teknik itu digunakan untuk mencapai kerapian, kemantapan berbusana (besus), dan supaya tidak mengganggu saat bergerak.

c. Kesungguhan (intensity)

Kesungguhan merupakan salah satu ciri dari benda yang memiliki nilai estetik. Kesungguhan atau intensitas yang dimaksud adalah keadaan suatu benda yang memiliki kualitas yang baik. Sebuah karya tari harus memiliki kualitas yang baik dari susunan tari, pelaku/ penari, maupun saat dipertunjukannya. Kualitas itu akan membuat karya tari memiliki nilai estetik, karena dengan kualitas sajian yang baik maka karya tari itu akan mampu mengungkapkan rasa, sehingga memiliki kemantapan estetik.

Tari Srimpi Pandhelori di Mangkunegaran memiliki kualitas. Hal itu 
dapat dirasakan dari penyusunan medium ungkap yang digunakan, mampu mengungkapkan nilai-nilai kehidupan sebagai isi tari Srimpi atau Pandhelori wujud, atau esensi yang inggin diungkapkan.

Kualitas tari Srimpi Pandhelori juga dapat dirasakan dari kesatuan, kerumitan, dan variasi medium ungkap yang digunakan. Elemen-elemen pembentuk tari Srimpi Pandhelori memiliki kesatuan, sehingga bisa mmencapai tataran kualitas rasa yang dalam. Tari Srimpi Pandhelori memiliki variasi yang dapat dirasakan ada pada motif gerak, karawitan tari, dan tata busana yang digunakan. Variasi medium ungkap itu dapat memberi kesan dinamis sehingga tidak monoton.

\section{Nilai-nilai kehidupan}

Tari Srimpi Pandhelori di Mangkunegaran memiliki nilai estetik karena di dalamnya mampu mengungkapkan nilainilai kehidupan. Menurut Dharsono Sony Kartika nilai-nilai yang ada dalam sebuah karya seni (tari) dipenga-ruhi pandangan, gagasan, pijakan, dan latar belakang budaya masing-masing daerah (Kartika, 2007a: 50). Hal itu menyebabkan tari Srimpi Pandhelori dipengaruhi pandang-an, pijakan, dan gagasan masya-rakat Jawa serta Pura Mangku-negaran.

Nilai-nilai yang terkandung pada tari Srimpi Pandhelori di-pengaruhi oleh pandangan, pijakan dan gagasan masyarakat Jawa, karena tari Srimpi Pandhelori hidup dan berkembang di lingkungan masyarakat Jawa. Menurut Wahyu Santoso Prabowo, orang Jawa memiliki kebiasaan untuk mewujudkan pandangan, gagasan, dan pemikirannya melalui simbolsimbol tertentu dalam berproses kesenian
(Slamet, 2014b: 75). Masyarakat Jawa telah memiliki pandangan dan gagasan sebuah karya tari dengan genre srimpi. Di dalam karya tari srimpi masyarakat Jawa membentuk simbol-simbol ungkapan nilainilai kehidupan berdasarkan pandangan dan gaga-sannya.

Meskipun tari Srimpi Pandhelori di Pura Mangkunegaran berasal dari Yogyakarta, namun nilai-nilai kehidupan tari Srimpi Pandhelori dipengaruhi pandangan, pijakan dan latar belakang budaya Pura Mangkunegaran. Hal itu disebab-kan karena Pura Mangkunegaran memiliki otoritas estetis pada tari Srimpi Pandhelori, sehingga mem-pengaruhi kemantapan estetik tari Srimpi Pandhelori, baik dari bentuk maupun isi yang diungkapkan. Mangkunegaran memiliki otoritas estetis terhadap tari Srimpi Pandhelori, karena tari Srimpi Pandhelori sudah berada pada wilayah yang baru, yaitu Pura Mangkunegaran.

a. Nilai-nilai Kehidupan Masya-rakat Jawa

Tari Srimpi Pandhelori adalah salah satu bentuk karya tari dalam genre srimpi. Wahyu Santoso Prabowo dalam buku Garan Joged menjelaskan bahwa tari srimpi merupakan sikap heneng, hening, hawas ing purwa sedyal sangkan paraning dumadi (dalam diam, keheningan, sadar akan asal dan tujuan hidup), juga sikap manembah, manekung, mrangkani yang bersuasana bakti kepada Tuhan Yang Maha Esa. Bersifat intuitif dan kontemplatif yang secara terus menerus tertuju pada sasaran pengenalan diri, penyatuan diri dengan Tuhan (teosentris) dan jagad raya (kosmosentris), serta mawas diri yang tulus (Slamet, 2014b: 81-82). Hal itu dapat dirasakan dari rasa sajian tari Srimpi Pandhelori, yang memiliki rasa menep, agung, wibawa, sareh, dan semeleh. Rasa itu 
diungkapkan melalui medium ungkap tari Srimpi Pandhelori.

Tari Srimpi Pandhelori berisi harapan dan cita-cita seorang raja. Di dalam tari Srimpi Pandhelori terdapat pesan moral, yang diung-kapkan melalui medium ungkap tari Srimpi Pandhelori. Pesan moral itu merupakan salah satu cara untuk mencapai harapan dan cita-cita raja. Pesan moral tari Srimpi Pandhelori adalah peperangan itu tidak baik, hanya menimbulkan perpecahan, maka meskipun me-miliki kekuatan yang hebat, lebih baik menjalin kebersamaan, karena dengan kebersamaan akan mempermudah untuk mencapai keten-traman, kesejahteraan, dan kemul-yaan hidup. Melalui bentuk garap tari Srimpi Pandhelori raja meng-ungkapkan pesan moral itu, untuk menuntun masyarakatnya dalam mencapai kedamaian, ketentraman, dan kesejahteraan hidup. Kedamai-an, ketentraman, kesejahteraan hi-dup merupakan harapan dan cita-cita dari seorang raja.

Tari srimpi merupakan tari yang masuk dalam golongan joged pasamuwaning agami, yang disebab-kan karena katitik saking lebeting panabuhipun gangsa saha alon lan tajem ing panjoged (Helsdiengen, 1925: 16). Dapat dipahami bahwa tari Srimpi Pandhelori merupakan joged pasamuwaning agami, karena menggunakan karawitan tari se-buah gending (panabuhipun gangsa), dan memiliki ketenangan serta diperlukannya konsentrasi dan penjiwaan yang mendalam dalam menarikannya (sareh, semeleh dan menep).

Tari Srimpi Pandhelori di Pura Mangkunegaran menggunakan gending Jawa dengan nada-nada (alunan-alunan lagu) yang me-nimbulkan rasa nikmat. Gending yang digunakan pada tari Srimpi Pandhelori, tersusun secara baik, dapat menimbulkan rasa indah dan halus, serta dapat membawa jiwa manusia kesuasana luhur. Di dalam Serat Sastra Gendhing dijelaskan bahwa, suara indah yang timbul dari seperangkat gamelan ageng dapat memberitakan persatuan hamba dan Tuhan (Sri, 1972: 336). Hal itu membuktikan bahwa dari rasa gending yang digunakan, tari Srimpi Pandhelori mampu meng-ungkapkan nilai religius, sebagai salah satu karya tari yang masuk dalam joged pasamuwaning agami.

Tari srimpi merupakan salah satu simbol dari dua sisi yang saling berlawanan yaitu baik dan jahat, gelap dan terang, bumi dan langit. Tari srimpi adalah karya tari yang disajikan oleh dua pasang perempuan, yang dapat digambarkan sebagai setangkep gula klapa dua sisi yang berlawanan (Suharto, 1990: 53). Tari Srimpi Pandhelori terdiri dari setangkep gula klapa dari dua sisi yang berlawanan. Keempat penari tari Srimpi Pandhelori mampu memberikan gambaran mengenai setangkep dua sisi yang berlawanan. Peperangan batak dengan gulu merupakan selirang dari dua sisi yang berlawanan, kemudian ditambah selirang deng-an peperangan yang dilakukan dhadha dengan buntil, sehingga menjadi setangkep gula klapa dua sisi yang berlawanan.

Buku Kawruh Joged Mataram menjelaskan bahwa peperangan atau konflik pada tari srimpi menggambarkan keinginan untuk berebut kemenangan. Perebutan sebuah kemenangan itu sudah biasa, karena pada dasarnya isi dari dunia ini adalah dua sisi yang selalu berlawanan. Apabila dari kedua sisi yang berlawanan ter-sebut dapat bersatu, yang buruk dapat bergabung dengan kebaikan, serta yang baik dapat menuntun keburukan untuk menuju 
kebaikan, maka akan dapat mencapai kemulyaan, kautaman, dan keluhur-an. Bersatunya kedua sisi yang berlawanan itu dinamakan dengan loro-loroning atunggal atau curiga manjing warangka (Brontodiningrat, 1981: 19). Loro-loroning atunggal atau curiga majing warangka dapat dikatan nyawiji. Nyawiji yang dimaksud adalah kemampuan untuk bersatu dengan Tuhan, alam, maupun dengan sesama manusia. Keseimbangan dan pengendalian diri diperlukan untuk nyawiji baik dengan Tuhan, alam, maupun sesama manusia, sehingga mampu mencapai kemulyaan lahir dan batin.

Bentuk gerak, tata rias dan busana yang sama, serta konflik yang seimbang (tidak ada yang kalah dan menang) pada tari Srimpi Pandhelori, mampu meng-ungkapkan keselarasan dan kese-imbangan (equilibrium). Pengendali-an diri dapat dirasakan dari, setelah terdapat konflik yang seimbang, keempat penari mundur, kemudian meletakan properti senjata yang digunakan. Keempat penari setelah meletakan senjata, bersatu menjadi satu keutuhan yang harmonis. Kesatuan yang utuh dapat dilihat dan dirasakan dari bentuk gerak dan arah hadap yang sama, serta bentuk pola lantai yang melingkar dan simetris.

Pola lantai tari Srimpi Pandhe-lori memiliki pola dasar yang me-lingkar dan simetris. Pola lantai melingkar yang dibentuk oleh se-pasang penari (selirang) pada tari Srimpi Pandhelori mampu meng-ungkapkan keseimbangan dan ke-satuan alam dari dua sisi yang ber-lawanan, karena memiliki bentuk yang menyerupai simbol Yin dan Yang. Yin adalah kegelapan dalam simbol warna hitam dan Yang adalah penerang dengan simbol warna putih. Keduanya saling berhadapan dengan seimbang laksana roda yang berputar. Simbol ini merupakan lambang penyadar-an akan hakekat kehidupan ma-nusia tentang sifat yang telah menjadi kodrat keilahian manusia yaitu kebaikan dan keburukan (Kresna, 2010: 63-64).

Tari Srimpi Pandhelori di Mangkunegaran merupakan simbol pengendalian diri dan keseimbang-an alam dalam kosmologi Jawa. Keempat penari Tari Srimpi Pandhelori merupakan gambaran makrokosmos dan mikrokosmos. Wahyu Santoso Prabowo menjelaskan makrokosmos adalah jagad raya atau alam semesta. Di dalam tari srimpi ditandai dengan empat kekuatan yang memiliki energi dari alam semesta, diantara-nya dari empat arah mata angin, yaitu utara, timur, selatan, dan barat. Selain itu energi yang dimiliki oleh alam juga ditandai dengan empat elemen yang sangat dibutuhkan untuk kelangsungan hidup manusia, yaitu api, angin, air, dan tanah. Keseimbangan alam perlu dijaga karena manusia tidak bisa hidup tanpa energi-energi alam, dan apabila salah satu energi alam tersebut bergejolak maka akan terjadi kekacauan.

Mikrokosmos adalah jagad cilik atau jagading manungsa. Manusia di dalam dirinya memiliki empat hawa nafsu yaitu aluamah, mut-mainah, amarah dan sufiah. Aluamah adalah nafsu mencela kesalahan orang lain dan dirinya sendiri, mutmainah adalah nafsu kebaikan dengan jiwa yang tenang, amarah adalah nafsu yang mengajak berbuat jahat, dan sufiah adalah nafsu mudah tergoda karena bisikan-bisikan yang baik maupun yang buruk (Susetya, 2007: 8-9). Nafsu-nafsu pada diri manusia tersebut harus ada dalam ke-seimbangan dan pengendalian akal budi manusia, karena apabila tidak diseimbangkan 
dan dikendalikan maka akan tejadi kekacauan, yang merusak diri manusia.

Rasa sareh, semeleh, menep, dan antep pada tari Srimpi Pandhelori mampu mengungkapkan perwujudan keseimbangan, keselaras-an, dan pengendalian diri. Rasa itu mampu diungkapkan melalui ben-tuk gerak yang tenang dan meng-alir, serta didukung rasa gending yang digunakan. Keseimbangan, keselarasan, dan pengendalian diri juga tampak pada motif gerak yang sama, tata rias dan busana yang sama, serta konflik yang seimbang. Formasi atau gawang yang simetris dan pola lantai dengan bentuk dasar melingkar pada tari Srimpi Pandhelori, juga mampu mengungkapan wujud keseimbangan, keselarasan, dan pengendalian diri.

Tari Srimpi Pandhelori adalah tari klasik, yang pada umumnya dipentaskan di pendapa dengan empat saka guru. Pola lantai melingkar simetris pada tari Srimpi Pandhelori, yang disajikan di dalam empat saka guru menyerupai konsep mandala dalam pandangan hidup masyarakat Jawa. Konsep mandala merupakan konsep hub-ungan interaksi yang membentuk satu kesatuan dan keseimbangan kosmos. Lingkaran mandala adalah kosmos, keteraturan dan ketertiban semesta, harmoni sempurna yang hadir dalam ruang empat persegi (Kartika, 2007a: 161). Keempat penari tari Srimpi Pandhelori dalam satu kesatuan, membentuk pola lantai yang melingkar simetris. Bentuk pola lantai itu dilakukan dalam ruang empat persegi, yang dibentuk dari keempat saka guru pendapa. Pola lantai melingkar simetris yang dibentuk oleh empat penari, dalam ruang empat persegi, mampu mengungkapkan keteratur-an dan ketertiban semesta (kosmos) yang sempurna. b. Nilai-nilai Kehidupan Pura Mangkunegaran

Pura Mangkunegaran memiliki beberapa konsep kehidupan yang diungkapkan dalam tari Srimpi Pandhelori. Konsep kehidupan itu merupakan nilai-nilai kehidupan masyarakat Pura Mangkunegaran yang menjadi sebuah pandangan, dan pijakan Pura Mangkunegaran dalam menjalani kehidupan di dunia ini. Nilai-nilai kehidupan Pura Mangkunegaran yang di-ungkapkan dalam tari Srimpi Pandhelori adalah konsep Surya Sumirat, konsep Tebu Sauyun, dan konsep Satriya Pinandhita.

Menurut Wahyu Santoso Prabowo Surya Sumirat memiliki arti pancaran sinar matahari dalam memberikan kehidupan jagad raya dengan isinya. Matahari adalah kekuatan energi yang dengan ketulusannya, kerelaanya, tanpa pamrih, tanpa mengharapkan balasan atau imbalan, tetap me-mancarkan sinar kehidupan bagi kepentingan mamayu hayuning bawana (Slamet, 2014b: 81). Surya Sumirat adalah sebuah konsepsi manusia hidup harus memiliki watak seperti matahari yaitu selalu memberi dengan tulus tanpa meng-harapkan imbalan dan keuntungan pribadinya (Rusini, 1999:27-28).

Tari Srimpi Pandhelori meng-angkat dua tokoh dalam Serat Menak, yaitu Sudarawerti dan Sirtu-pelaheli. Konsep Surya Sumirat dapat dirasakan dari ketulus ikhlasan Sudarawerti dan Sirtu-pelaheli yang rela berkorban me-nolong Amir Ambyah dari Penjara, serta merawat dan memenuhi segala kebutuhan Amir Ambyah. Konsep Surya Sumirat juga dapat dirasakan dari kedua tokoh ter-sebut, dimana keduanya memiliki rasa saling memberi dan berbagi tanpa pamrih, karena Sirtupelaheli dan Sudarawerti menikah kepada orang yang sama. 
Konsep Tebu Sauyun adalah sebuah konsep yang berisinilai kebersamaan. Konsep ini yang digunakan oleh K.G.P.A.A. Mangkunagara I ketika bertempur untuk melawan musuh-musuhnya, hingga akhirnya sampai menjadi seorang adipati di Pura Mangku-negaran. Konsep Tebu Sauyun dalam tari Srimpi Pandhelori dapat dirasakan pada cerita yang di-angkat, karena cerita yang diangkat memiliki nilai kebersamaan. Nilai kebersamaan dapat dirasakan dari Sirtupelaheli dan Sudarawerti yang memilih mengakhiri peperangan, kemudian bersamasama menyela-matkan Amir Ambyah. Nilai ke-bersamaan juga dapat dirasakan dari bentuk gerak yang sama yang dilakukan bersamaan dalam satu keutuhan, kesatuan rasa yang dibangun (kempel) dari keempat penari, dan interaksi-interaksi dari pandangan mata, arah hadap tubuh, dan garis-garis gerak yang digunakan.

Satriya Pinandhita adalah sebuah konsep padangan hidup yang terbentuk dari Tiji Tibeh dan Surya Sumirat. Menurut Hari Mulyatno Tiji Tibeh memiliki sifat kesatria dan Surya Sumirat memiliki sifat seperti pendeta. Kedua konsep pandangan hidup tersebut menjadi satu ke-satuan dan merupakan Dwi Tunggal yang tidak bisa dipisah-kan, yang kemudian dikenal dengan konsep Satriya Pinandhita. K.G.P.A.A. Mangkunagara I memiliki konsep pandangan hidup Satriya Pinandhita yang ditunjukan dengan sifat yang dimilikinya, yaitu memiliki sifat kesatriya yang gagah berani bertempur melawan musuhnya, dan memiliki sifat memberi dan mengasihi seperti sifat pendeta (Rusini, 1999: 27-29).

Konsep Satriya Pinandhita dapat dirasakan dari cerita yang di-angkat dalam tari Srimpi Pandhe-lori. Dari cerita yang diangkat sudah dapat dirasakan memiliki tema peperangan yang menunju-kan sikap kesatriya. Keduanya ber-perang untuk memperjuangkan apa yang menjadi harapan dan cita-citanya yaitu menyelamatkan dan menikah dengan Amir Ambyah. Sikap kesatria juga dapat dirasakan setelah Sudarawerti dan Sirtupe-laheli bersatu. Keduanya tanpa rasa takut menyelamatkan Amir Am-byah dari penjara. Sikap pendeta dapat dirasakan dari sifat Sirtu-pelaheli dan Sudarawerti yang me-miliki sifat saling menerima, sabar, ikhlas, dan mau berbagi cinta dan kasih sayangnya. Meskipun keduanya memiliki kekuatan dan ke-beranian seperti kesatriya, namun Sudarawerti dan Sirtupelaheli me-milih untuk saling menerima dan membagi cinta serta kasih sayang-nya.

Tari Srimpi Pandhelori meng-gunakan kain dengan desain samparan, yang digerakan ke kanan dan ke kiri dengan kaki. Samparan dalam pandangan hidup orang Jawa sangat terkait dengan seorang perempuan. Perempuan menurut pandangan Jawa pada umunya memiliki sifat yang lemah lembut, halus, dan ramah, namun di balik semua itu perempuan Jawa juga harus memiliki kecekatan, kesigap-an, dan kegagahan. Samparan da-lam sebuah karya tari merupakan simbol dari kekuatan, kesigapan, dan kegagahan wanita Jawa. Mes-kipun dalam tari bedhaya maupun srimpi, yang menggunakan bentuk gerak yang halus, lembut, dan anggun, namun memiliki kekuatan, kesigapan, dan kegagahan yang muncul dari permainan samparan yang diseblakan ke kanan dan ke kiri (Prabowo, wawancara 13 November 2017).

Permainan samparan dalam tari Srimpi Pandhelori, yang dilakukan bersamaan dengan bentuk gerak yang mengalir, dengan 
garis-garis yang terkesan lentur, dan tolehan kepala ke kanan dan ke kiri yang dapat memberi rasa halus, lembut, dan anggun, mampu mengungkap-an konsep Satriya Pinandhita. Per-mainan samparan pada tari Srimpi Pandhelori mampu mengungkap-kan sikap seorang kesatriya yang gagah, cekatan, dan sigap, sedang-kan rasa halus, lembut, dan anggun mampu mengungkapkan sifat pendeta.

Tari Srimpi Pandhelori meng-gunakan pandangan mata tajem diagonal ke bawah, dengan jarak pandang kurang lebih tiga meter kedepan, serta menggunakan adeg pacak kelir, yang mampu meng-ungkapkan rasa gagah. Bentuk gerak tangan yang digunakan me-ngalir, lembut, dan halus, sehingga mampu mengungkapkan rasa sareh dan semeleh. Bentuk adeg, pan-dangan mata, dan bentuk gerak itu mampu mengungkapkan sifat Satriya Pinandhita.

Tari Srimpi Pandhelori memiliki rasa sajian gagah, sigrak, agung, wibawa, menep, dan antep. Rasa itu dibentuk dengan medium ungkap tari Srimpi Pandhelori. Rasa yang dibentuk dari medium ungkap tari Srimpi Pandhelori itu mampu mengungkapkan konsep Satriya Pinandhita. Rasa gagah, sigrak, agung, dan wibawa mampu mengungkapkan sifat kesatriya, sedang-kan rasa menep dan anteb mampu mengungkapkan sifat pendeta.

\section{PENUTUP}

Tari Srimpi Pandhelori adalah salah satu karya tari yang berasal dari KBW Yogyakarta, namun terdapat teknik pelaksanaan gerak yang berbeda. Perbedaan dapat dilihat dan dirasakan dari cara menggerakan kepala, lengan, tangan, tubuh, dan kaki. Perbedaan teknik pelaksanaan gerak menye-babkan tari Srimpi Pandhelori di Mangkunegaran memiliki karakteristik tersendiri, kemudian disebut dengan nama Tari Srimpi Pandhelori gaya Mangkunegaran.

Tari Srimpi Pandhelori di Pura Mangkunegaran memiliki nilai estetik dari bentuk maupun isi yang menjadi satu kesatuan. Nilai bentuk tari Srimpi Pandhelori di Pura Mangkunegaran dapat di-rasakan dari kesatuan, kerumitan, dan kualitas yang dimiliki. Isi tari Srimpi adalah nilai-nilai kehidupan masyarakat Jawa dan Pura Mangkunegaran. Nilai-nilaikehidupan itu mampu diungkapkan melalui lambanglambang sensa medium ungkap tari Srimpi Pandhelori. Nilai-nilai kehidupan masyarakat Jawa yang diungkapkan dalam tari Srimpi Pandhelori adalah nilai religius dan nilai keseimbangan, dan pengendalian diri.

Nilai-nilai kehidupan Pura Mang kunegaran yang diungkapkan dalam tari Srimpi Pandhelori, yaitu nilai dalam konsep Surya Sumirat, konsep Tebu Sauyun, dan konsep Satriya Pinandhita.

\section{DAFTAR PUSTAKA}

Gie, The Liang.

1976. Garis Besar Estetika. Yogyakarta: Penerbit Karya.

Hadi, Y. Sumandiyo.

2003. Aspek-aspek Dasar Koreografi Kelompok. Yogyakarta: eLKAPHI.

Helsdiengen, Van B. - Schoevers.

1925. Serat Bedhaya Srimpi. Weltevreden: Bale Pustaka.

Kartika, Dharsono Sony dan Nanang Ganda Prawira.

2004. Pengantar Estetika. Bandung: Rekayasa Sains. 
Kartika, Dharsono Sony.

2007a. Budaya Nusantara, Kajian Konsep Mandala dan Tri-Loka terhadap Pohon Hayat pada Batik Klasik. Bandung: Rekayasa Sains.

.2007b. Estetika. Bandung: Rekayasa Sains. Kresna, Ardian.

2010. Semar dan Togog Yin Yang dalam Budaya Jawa. Yogyakarta: Narasi.

MD, Slamet.

2014a. Barongan Blora Menari di atas Politik dan Terpaan Zaman. Surakarta: Citra Sains.

2014b. Garan Joged Sebuah Pemikiran Sunarno. Surakarta: Citra Sains.

Parker, De Witt H.

1979. “Dasar-dasar Estetika,"di Indonesiakan oleh SD. Humardani. Sub Proyek ASKI Proyek Pengembangan IKI.

Prabowo, Wahyu Santoso, dkk.

2007. Sejarah Tari Jejak Langkah Tari di Pura Mangkunegaran. Surakarta: ISI Press. Prihatini, Nanik Sri, dkk.

2007. Ilmu Tari Joged Tradisi Gaya Kasunanan Surakarta. Surakarta: ISI Press.

Rusini.

1999. "Bedhaya Surya Sumirat Kreasi Pura Mangkunegaran di Akhir Abad XX." Laporan Penelitian Perorangan STSI Surakarta.

Simatupang, Lono.

2013. Pergelaran Sebuah Mozaik Penelitian SeniBudaya. Yogyakarta: Jalasutra.
Soedarsono, R.M.

1978. "Diktat Pengantar Pengetahuan dan Komposisi Tari." ASTI Yogyakarta.

Sri, Almanak Dewi.

1972. Serat Sastra Gendhing Sekar Macapat. Yogyakarta: Kamajaya Up. Indonesia. Suharti, Theresia.

1990. “Tari Mangkunagaran Suatu Pengaruh Bentuk dari Gaya Dalam Dimensi Kultural 1916-1988." Thesis untuk memenuhi sebagian persyaratan guna mencapai drajat Sarjana S-2 program pasca sarjana Universitas Gadjah Mada Yogyakarta. Suharto, Benedictus.

1998. Dance Power: The Concept Of Mataya in Yogyakarta Dance, Benedictus Suharto. Bandung: Sastrataya-Masyarakat Seni Pertunjukan Indonesia.

Susetya, Wawan.

2007. Pengendalian Hawa Nafsu Orang Jawa. Yogyakarta: Narasi.

\section{NARASUMBER}

Sri Hartono, R.T. (75 tahun), empu karawitan di Mangkunagaran. Keprabon, Banjarsari, Surakarta.

Rusini (68 tahun), pelatih tari di Mangkunegaran dan pensiunan dosen Jurusan Tari ISI Surakarta. Keprabon, Banjarsari, Surakarta.

Umiyati Sri Warsini (61 tahun), pelatih tari, dan pengeprak di Mangkunagaran. Keprabon, Banjarsari, Surakarta.

Wahyu Santoso Prabowo (65 tahun), dosen ISI Surakarta. Mojosongo, Jebres, Surakarta 